\title{
Homozygous deletion of early growth response 1 gene and critical limb ischemia after vascular ligation in mice: Evidence for a central role in vascular homeostasis
}

\author{
Paul Schalch, MD \\ Gerald Patejunas, $\mathrm{PhD}^{\mathrm{a}}$ \\ Mauricio Retuerto, $\mathrm{MA}^{\mathrm{a}}$ \\ Sorin Sarateanu, MD ${ }^{\mathrm{a}}$ \\ Jeffrey Milbrandt, $M D^{\mathrm{b}}$ \\ Geeta Thakker, $\mathrm{PhD}^{\mathrm{c}}$ \\ David Kim ${ }^{\mathrm{a}}$ \\ JoAnn Carbray ${ }^{\mathrm{a}}$ \\ Ronald G. Crystal, MD ${ }^{\mathrm{d}}$ \\ Todd K. Rosengart, MD ${ }^{a, e}$
}

From Evanston Northwestern Healthcare, Evanston, Ill, ${ }^{\text {a }}$ Washington University, St Louis, Mo, ${ }^{\text {b }}$ Lexicon Genetics, Inc, The Woodlands, Tex, ${ }^{\mathrm{c}}$ Weill Medical College of Cornell University, New York, NY, ${ }^{\mathrm{d}}$ and Feinberg School of Medicine of Northwestern University, Chicago, Ill. ${ }^{\mathrm{e}}$

Supported in part by the National Institutes of Health/National Heart, Lung, and Blood Institute (R01 66981, R01HL57318, and R01HL61719), Evanston Northwestern Healthcare Women's Auxiliary Fund (Evanston, Ill), and Gen Vec, Inc (Rockville, Md).

Received for publication Nov 26, 2003; revisions requested Jan 20, 2004; accepted for publication Feb 23, 2004.

Address for reprints: Todd K. Rosengart, MD, 2650 Ridge Ave, Burch 100, Evanston, IL 60201 (E-mail: trosengart@enh. org).

J Thorac Cardiovasc Surg 2004;128: $595-601$

$0022-5223 / \$ 30.00$

Copyright ( $\odot 2004$ by The American Association for Thoracic Surgery

doi:10.1016/j.jtcvs.2004.02.036
Background: The early growth response 1 gene (Egrl) encodes for an immediate to early response transcription factor that is upregulated by changes in vascular strain and hypoxia and in turn upregulates the downstream expressions of a number of angiogenic growth factors. We therefore hypothesized that early growth response 1 may be a critical early messenger governing revascularization in the setting of acute vascular occlusions.

Methods: C57 BL/6 mice deficient in the Egrl gene (knockout) and their wild-type litter mates underwent ligation and excision of the femoral artery with or without the previous administration of $2.7 \times 10^{9}$ particle units of an adenoviral vector coding for the vascular endothelial growth factor gene (VEGF) or Egrl. Distal hind limb perfusion was serially measured in these animals with laser Doppler perfusion imaging.

Results: Wild-type mice $(n=9)$ had nearly complete restitution of hind limb perfusion by day 35 after ligation. In contrast, all noninjected Egrl knockout mice $(\mathrm{n}=5)$ had severe ipsilateral limb necrosis develop between 1 and 4 days after ligation $(P<.0001)$. Egrl knockout mice injected with $V E G F$ vector $(\mathrm{n}=4)$ demonstrated significantly improved perfusion relative to baseline by postligation day 28 , which persisted to postligation day $35(P<.05)$. Egrl knockout animals injected with $E g r l$ vector $(\mathrm{n}=7)$ demonstrated a partial recovery of hind limb perfusion relative to $V E G F$ vector-treated knockout animals at postligation day 4 ( $P$ $<.01)$, which persisted to day 35 .

Conclusions: These findings suggest that early growth response 1 plays a pivotal role in reperfusion responses to vascular occlusion in mice and possibly other mammals.

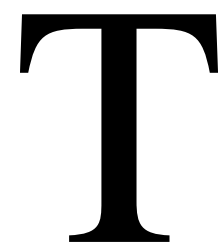

he demonstrated ability of ischemia and hypoxia to upregulate the expression of a number of angiogenic growth factors and their receptors has led to the assumption that ischemic upregulation of these growth factors underlies the development of collateral vessels in the setting of vascular occlusion. ${ }^{1-4}$ Moreover, the apparent role of these growth factors in the endogenous processes of angiogenesis and collateral vessel formation has led to the development of a strategy of thera- 
peutic angiogenesis, in which exogenous growth factors are administered to ischemic tissues to enhance the reperfusion of these tissues. ${ }^{5-8}$

Although a mechanism of ischemic upregulation of growth factor expression as a stimulus for collateral vessel formation intuitively follows from the known biology of these proteins, several lines of evidence contradict this premise. First, it has reasonably been noted that the tissues surrounding a point of vascular occlusion are unlikely to be ischemic, because tissues proximal to the vascular occlusion will be perfused by the patent upstream vasculature and tissues immediately distal to the occlusion point will likely receive blood flow through existing vascular branches originating upstream from the ligation point. ${ }^{9,10}$ Second, the therapeutic administration of individual growth factors has shown that these proteins acting alone primarily stimulate angiogenesis (capillary development) rather than arteriogenesis (the development of larger collateral vessels). ${ }^{7,8,11-15}$

The early growth response (EGR) 1 transcription factor represents an intriguing alternative candidate transponder capable of sensing the biophysical stimuli associated with vascular occlusion and translating these stimuli into the activation of appropriate effector molecules capable of inducing angiogenesis and arteriogenesis. ${ }^{16-19}$ More specifically, the activity of EGR-1 is modulated by changes in vascular wall shear stress such as would occur in the setting of an acute vascular occlusion..$^{20}$ EGR-1 in turn has been shown to directly or indirectly upregulate the expression of numerous vascular growth factors, including vascular endothelial growth factor (VEGF), that are capable of inducing or supporting angiogenesis and that may in concert be capable of inducing collateral vessel formation. ${ }^{16-21}$

On the basis of these considerations, we hypothesized that vascular occlusion could result in EGR-1 upregulation, which in turn could induce revascularization through the expression of downstream growth factors. We tested this hypothesis by examining distal reperfusion after femoral artery ligation in wild-type and Egrl knockout animals.

\section{Methods}

\section{Egr1 Knockout Animals}

A colony of Egrl -/- (knockout) C57 BL/6 mice (gift of Dr Jeffrey Milbrandt, Washington University, St Louis, Mo) ${ }^{22,23}$ was established at the Coon Research Center at Evanston Northwestern Healthcare through standard breeding procedures. Animal handling at all times was in accordance with institutional animal care and use committee guidelines. All animals received humane care in compliance with the "Guide for the Care and Use of Laboratory Animals" (http://www.nap.edu/catalog/5140.html). Animals selected from this colony underwent genotyping at 25 days after birth, after which knockout and wild-type animals underwent experimental studies at approximately 2 to 4 months of age.

\section{Gene Transfer Vectors}

The adenovirus Egrltransfer vector (AdEgr) used for these studies was also a gift of J. Milbrandt. The replication-defective VEGF transfer vector (AdVEGF) used in these studies was an $\mathrm{E}^{-} \mathrm{a}^{-}$, partial $\mathrm{E} \mathrm{b}^{-}$, partial $\mathrm{E}^{-}$adenovirus vector based on human adenovirus serotype 5 prepared as previously described elsewhere. ${ }^{24-26}$ As a negative control, a similar adenovirus containing no gene in the expression cassette (AdNull) was used. Vector competency was assessed on HT1080 cells (ATCC No. CCl-121; American Type Culture Collection, Manassas, Va), which were treated with 50 particle units (pu)/cell of AdVEGF, AdEgr, or AdNull, or with saline solution. Culture media was collected 48 hours later and subjected to enzyme-linked immunosorbent assay (VEGF analysis), ${ }^{26}$ or cells were harvested into Trizol reagent (Invitrogen, Carlsbad, Calif), and RNA was purified, reverse transcribed, and subjected to semiquantitative polymerase chain reaction (PCR) with rat Egrl primers (GenBank Accession No. NM012551). ${ }^{27}$

\section{Analysis of Egr1 Expression After Vascular Occlusion} In initial studies, male Sprague-Dawley rats (250-350 g; Harlan Sprague Dawley, Inc, Indianapolis, Ind) treated in accordance with institutional animal care and use committee guidelines were anesthetized with ketamine $(80 \mathrm{mg} / \mathrm{kg})$ and xylazine $(12 \mathrm{mg} / \mathrm{kg})$ administered intraperitoneally. A midline abdominal incision was then made, and the left common femoral artery was identified and ligated. The left iliac and femoral arteries upstream from the vascular ligation point were harvested 30,60, or 120 minutes later, and the right iliac and femoral arteries were taken as control specimens for Northern blot analysis. The harvested vascular tissues were homogenized in $1.0 \mathrm{~mL}$ Trizol reagent (Invitrogen), and the total RNA was isolated according to the manufacturer's instructions. RNA was then dissolved in water and quantified, and 10 $\mu \mathrm{g}$ of total RNA was loaded on a $1 \%$ formaldehyde agarose gel. After electrophoresis, RNA was transferred overnight by capillary force to a Zeta-probe GT Genomic Tested Blotting Membrane (Bio-Rad Laboratories Inc, Hercules, Calif) in $10 \times$ standard saline citrate solution. The blot was ultraviolet cross-linked for 2 minutes and then prehybridized with Hybrisol TM I (Oncor, Inc, Gaithersburg, Md) for 30 minutes before addition of phosphorus 32 randomly primed labeling probe for mouse Egrl (GenBank Accession No. NM-007913). The membrane was hybridized overnight, washed twice at room temperature for 20 minutes with $2 \times$ standard saline citrate solution plus $0.2 \%$ sodium dodecylsulfate and then twice for 20 minutes with $0.2 \times$ standard saline citrate solution plus $0.2 \%$ sodium dodecylsulfate at $55^{\circ} \mathrm{C}$. The blot was then autoradiographed by exposure to X-ray film (X-Omat AR; Eastman Kodak Company, Rochester, NY), and the autoradiograph signal intensities were quantified with ImageQuant (Amersham Pharmacia Biotech, Inc, Piscataway, NJ).

\section{Genotyping}

All subsequent studies were performed in animals selected from the C57 BL/6 knockout mouse colony described previously. Genotyping of these animals was performed from tail tip tissues obtained after briefly placing the animals in an isoflurane chamber, as previously described elsewhere. ${ }^{28}$ 


\section{Vascular Ligation}

Wild-type or homozygous Egrl-deleted (knockout) animals (25-35 g) selected from the C57 BL/6 mouse colony were anesthetized with pentobarbital $(60 \mathrm{mg} / \mathrm{kg}$ intraperitoneally) after induction with a mixture of isoflurane $(3.5 \mathrm{~L} / \mathrm{min})$ and $100 \%$ oxygen ( $3 \mathrm{~L} / \mathrm{min}$ ). A midline abdominal incision was then made, and the proximal end of the femoral artery at the inguinal ligament and the distal portion of the saphenous artery were ligated with 4-0 silk. The artery and all side branches were then dissected free, and this entire vascular segment was removed. ${ }^{29}$ The incision was then closed, and the animal was allowed to recover according to standard protocols.

\section{Laser Doppler Perfusion Study}

Laser Doppler perfusion imaging was used to measure distal hind limb perfusion before the operation and at serial time points after vascular excision. Duplicate laser Doppler perfusion images were obtained in a blinded manner with an LDPI system (Perimed, Jarfalla, Sweden) through clipped and depilated hind limb skin surfaces after placing the mice on a $37^{\circ} \mathrm{C}$. heating pad for 10 minutes. Regions of interest (ROIs) encompassing either the entire ligated limb or the contralateral nonligated hind limb were analyzed with accessory software provided by the manufacturer, as previously described elsewhere. ${ }^{29}$ More specifically, the ROIs were determined from black and white images (without perfusion data) of the ventral surface of the animals by placing a standard, computer-generated circle around the most distal aspect of each hind limb, after which the system software was used to calculate a mean intensity of Doppler signal within the ROI encompassed by the circle. To minimize data variables caused by ambient light and temperature, a perfusion index for each animal was expressed as the average of the ratios of the ROIs for the ligated limb versus the contralateral, nonligated limb.

\section{Adenoviral Vector Injection}

In initial studies assessing in vivo activity of the AdEgr vector, male Sprague-Dawley rats were prepared as described previously, and three 5- $\mu \mathrm{L}$ injections of AdVEGF, AdEgrl, or AdNull $(4 \times$ $10^{9} \mathrm{pu}$ /injection, total dose $1.2 \times 10^{10} \mathrm{pu}$ ) or an equal volume of phosphate-buffered saline solution were made through a midline laparotomy into the proximal hind limb musculature. The animals were allowed to recover, and the proximal hind limb musculature was then harvested 48 hours later and subjected to semiquantitative PCR analysis as previously described elsewhere. ${ }^{27}$

Administration of AdVEGF or AdEgr vectors was performed 24 hours before vascular ligation in subsets of wild-type and Egrl knockout animals. These mice were anesthetized as described previously, and an incision in the abdominal midline was made, allowing exposure of the femoral artery, after which three 5 $\mu \mathrm{L}$-injections of AdVEGF or AdEgrl $\left(9 \times 10^{8}\right.$ pu/injection, total dose $2.7 \times 10^{9} \mathrm{pu}$ ) were made into the proximal hind limb musculature. Animals were allowed to recover for 24 hours, after which an ipsilateral double femoral artery ligation and excision was performed as described previously.

\section{Statistical Analysis}

Data are expressed as mean \pm SD. Either $\chi^{2}$ analysis or Student $t$ test was used to show significance, as appropriate.

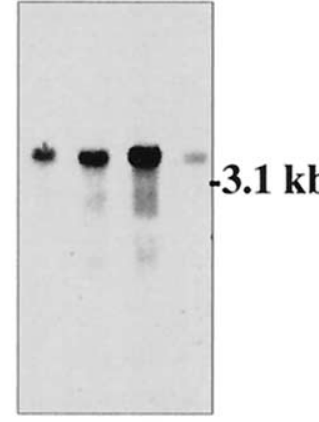

Probe: EGR-1

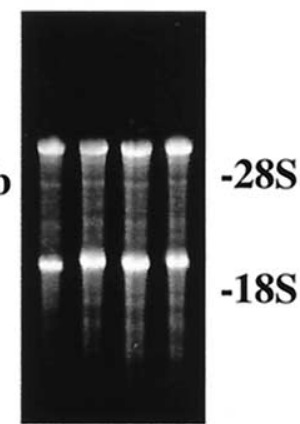

EtBr gel
Figure 1. Northern blot analysis of EGR-1 after iliac artery ligation in rats. Left femoral artery was ligated, and proximal iliac and femoral arteries were harvested as indicated. Right iliac and femoral arteries were taken as control. Peak Egr1 expression is noted 60 minutes after ligation. Lanes: 1, nonligated control; 2, 30 minutes after ligation (1.6 $\times$ control); 3, 60 minutes after ligation $(2.1 \times$ control); 4, 120 minutes after ligation $(0.6 \times$ control). $E t B r$, Ethidium bromide.

\section{Results}

\section{Egr1 Expression}

Northern blot analysis of the iliofemoral vasculature harvested after femoral artery ligation performed in rats demonstrated an approximate 2-fold increase of Egrl messenger RNA expression, which reached a maximum 60 minutes after vascular ligation (Figure 1). Egrl expression was rapidly downregulated in these studies, returning to baseline levels within 120 minutes after ligation. Egrl signal upregulation was specific to the ipsilateral vascular tissues proximal to the vascular ligation point. Neither the distal ipsilateral nor the contralateral vasculature demonstrated a change from baseline in the level of Egrl expression (data not shown).

\section{Limb Ischemia in Egr1 Knockout Mice}

All noninjected Egrl knockout mice $(\mathrm{n}=5)$ and their wild-type littermates $(n=9)$ had severe hind limb ischemia develop immediately after vascular ligation (Table 1), as demonstrated by perfusion indices of $0.1 \pm 0.04$ and $0.2 \pm$ 0.05 , respectively $(P=.14)$, immediately after ligation (Figure 2). The wild-type mice demonstrated a rapid recovery of hind limb perfusion, generating an average perfusion index of $0.5 \pm 0.1$ at day 4 after ligation $(P<.05$ vs baseline), which increased to an index of $0.8 \pm 0.2$ by day 35 after ligation $(P<.01$ compared to baseline $)$. In contrast to the absence of observed morphologic or motor abnormalities by day 35 in wild-type mice, all noninjected Egrl knockout mice had severe necrosis of the ligated limb develop between 1 and 4 days after the procedure (Figure 


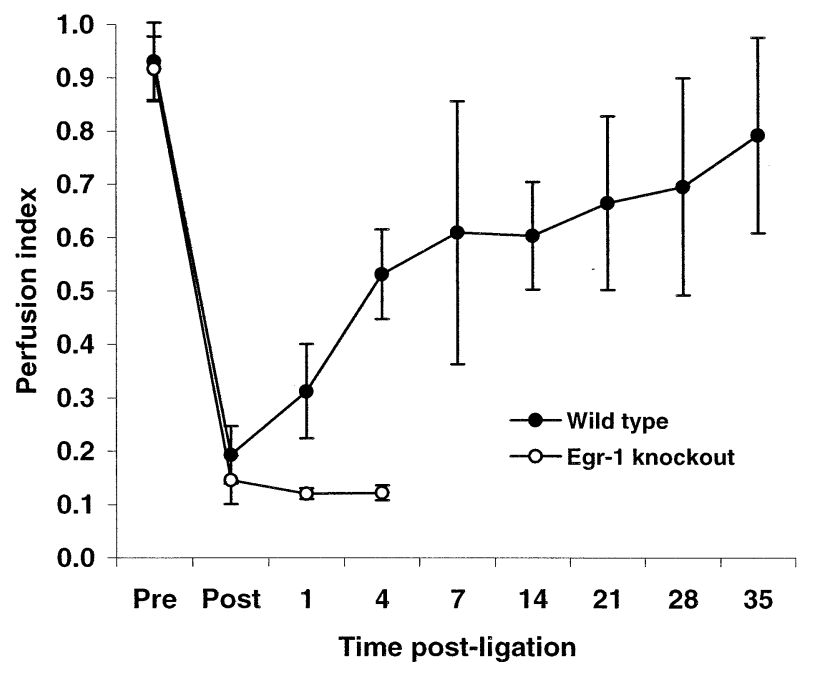

Figure 2. Distal hind limb perfusion after ipsilateral vascular excision in wild-type and Egr1 knockout C57 BL/6 mice. Perfusion index is calculated as described in Methods section from laser Doppler perfusion imaging of ligated and nonligated hind limbs.

Table 1. Limb necrosis in ligated wild-type and Egr1 knockout mice

\begin{tabular}{lll}
\hline & \multicolumn{2}{c}{ Limb necrosis } \\
\cline { 2 - 3 } Group & Yes & No \\
\hline Wild-type $(\mathrm{n}=9)$ & 0 & 9 \\
Egr1 knockout $(\mathrm{n}=5)$ & $5^{*}$ & 0 \\
Wild-type plus AdVEGF $(\mathrm{n}=5)$ & 0 & 5 \\
Egr1 knockout plus AdVEGF $(\mathrm{n}=4)$ & 0 & 4 \\
Egr1 knockout plus AdEgr1 $(\mathrm{n}=7)$ & 0 & 7 \\
\hline
\end{tabular}

${ }^{*} P<.0001$ versus wild type $\left(\chi^{2}\right.$ test).

3); this necrosis was so severe as to preclude further measurements beyond these time points $(P<.0001$ vs necrosis in wild-type animals; Table 1).

\section{AdVEGF and AdEgr Rescue}

The competencies of the AdVEGF and AdEgr vectors were first validated in vitro by enzyme-linked immunosorbent assay and semiquantitative PCR analyses, respectively (data not shown). Administration of AdEgr into the hind limb musculature of normal rats was then shown by semiquantitative PCR to induce an approximate 3- to 4-fold increase in Egrl expression relative to reduced glyceraldehyde-phosphate dehydrogenase standards, whereas AdVEGF administration demonstrated an intermediate increase and AdNull or saline solution administration induced no appreciable expression of Egrl expression 48 hours after administration (data not shown).

Egrl knockout mice injected with AdVEGF before ligation $(\mathrm{n}=4)$ demonstrated an absence of necrosis $(P=$
.0027 vs necrosis in untreated knockouts) and significantly improved perfusion index by postligation day 28 compared with the perfusion index immediately after ligation $(P<$ $.05)$. This improvement persisted to postligation day 35 (0.7 $\pm 0.2, P<.01)$ and approximated that observed in ligated wild-type animals (Figure 4). Egrl knockout animals injected with AdEgr $(\mathrm{n}=7)$ similarly demonstrated an absence of necrosis $(P=.0005$ vs necrosis in untreated knockouts) and improvement of hind limb perfusion; improvement was less than that observed in AdVEGF-injected knockouts through postligation day $4(0.2 \pm 0.04, P<.01)$ but then demonstrated a similar pattern of improvement relative to AdVEGF-treated knockouts through day 35 after ligation (Figure 5). Neither AdVEGF- nor AdEgr-treated knockout animals demonstrated morphologic or motor abnormalities by day 35 after ligation $(P<.003$ vs untreated knockouts).

\section{Discussion}

EGR-1 (also known as zif 268, TIS 8, nerve growth factor induced A, and Krox 24) is an 80- to 82-kd, 533-amino acid residue protein that is the prototypical member of the immediate to early gene family of zinc-finger transcription factors that includes EGR-2, EGR-3, and EGR-4. A growing body of data suggests that EGR-1 plays an important role in a number of vascular homeostatic mechanisms. ${ }^{16-21}$ Data in this study suggest the potential importance of EGR-1 in the normal reperfusion response to acute vascular occlusion. These findings include (1) the demonstration of rapid, transient upregulation of Egrl messenger RNA expression in arterial tissues in response to acute vascular occlusion (ligation) and (2) the near-total absence of reperfusion after vascular ligation in Egrl knockout animals, as quantified by laser Doppler analysis and confirmed by the finding of extensive tissue necrosis in the ligated limbs. Additional data demonstrating the "rescue" of the reperfusion defect in Egrl knockout animals by the administration of $\mathrm{AdEg} r$ in these studies is presented as a positive control for the Egrl defect in knockout animals, whereas the demonstration of reperfusion in Egrl knockouts treated with AdVEGF is consistent with an apparent downstream locus for VEGF in the EGR-1 signaling pathway.

The studies described in this report follow our previous observation of markedly upregulated expression of Egrl in a pneumonectomy and contralateral lung growth model. ${ }^{30}$ The apparent importance of Egrl expression in this model suggested to us that EGR-1 was critically responsive to changes in shear stress after vascular ligation, analogous to the hemodynamic changes expected with naturally occurring atherosclerotic vascular occlusions. These observations led us to suspect that EGR-1 might represent the previously "missing" signaling factor capable of translating the physiologic sequelae of vascular occlusion into the homeostatic 


\section{Wild Type}

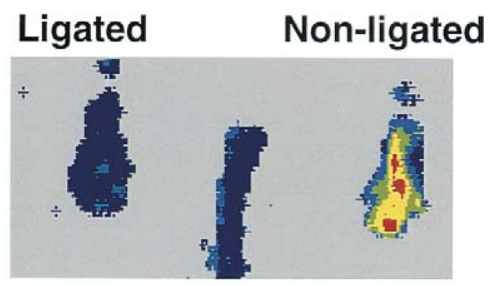

\section{Day 0}
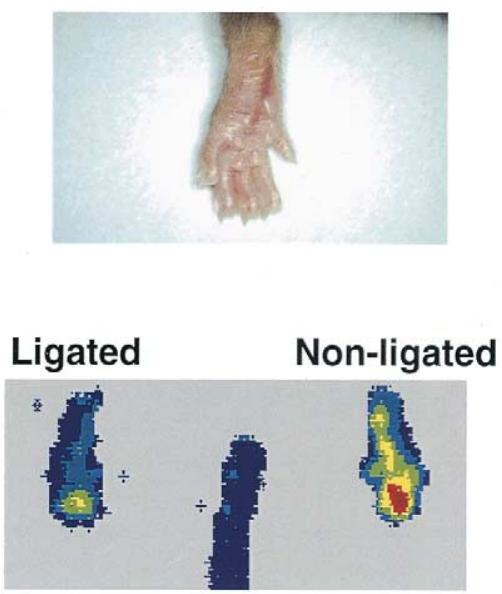

\section{Day 4}

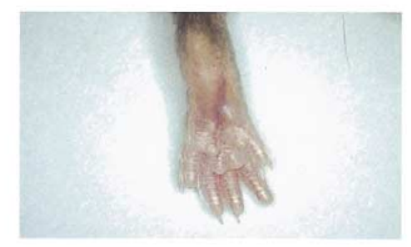

\section{Egr-1 Knockout}

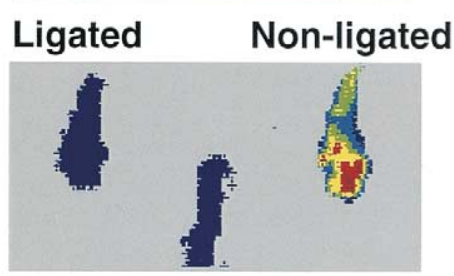

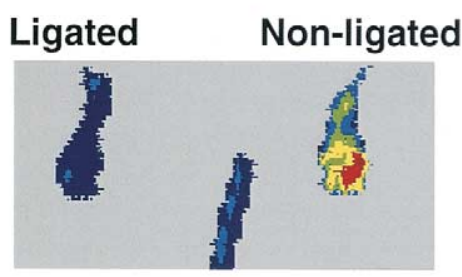

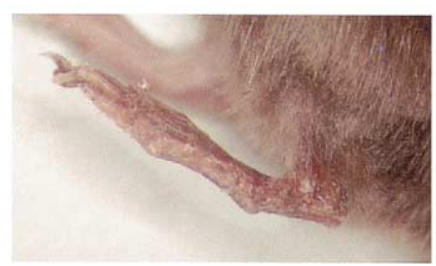

Figure 3. Laser Doppler perfusion images and macroscopic appearances of ligated and nonligated hind limbs of wild-type and Egr1 knockout mice. Perfusion is illustrated by means of color scale, with red-yellow being highest and blue-black being lowest. Perfusion images correlate with development of severe necrosis at indicated intervals after ligation.

response of collateral vessel formation that follows this biologic perturbation.

EGR-1 processing mechanisms are elegantly designed to translate physiologic factors as stress and hypoxia into modulation of gene expression and biologic responses. ${ }^{16-23}$ The responsiveness of Egrl to biophysical stimuli occurs through a series of serum response elements in the $E g r$ promoter region, to which a variety of intracellular proteins, such as serum response factor and ternary complex factor, can reversibly bind. These proteins are typically modified and activated by cytoplasmic kinases, which in turn are modulated by cytoplasmic and cell membrane stimuli, such as cell stretching (shear stress). The serum response elements promote the production of EGR-1, which then binds to the promoter region and enhances the expression of such genes as those for platelet-derived growth factor A and B, transforming growth factor $\beta$, tissue factor, urokinase-type plasminogen activator, and a number of the metalloproteinases responsible for angiogenesis and vascular formation.

Importantly, Egrl is inducibly expressed in many different cell types relevant to the vascular signaling mechanism presently under consideration, including endothelial cells, smooth muscle cells, fibroblasts, and leukocytes. Aside from shear stress and hypoxia, EGR-1 is also upregulated by thrombin, acidic fibroblast growth factor, basic fibroblast growth factor, epidermal growth factor, and VEGF. The ability of EGR-1 to upregulate and be upregulated by a number of proteins that act through autocrine and paracrine 


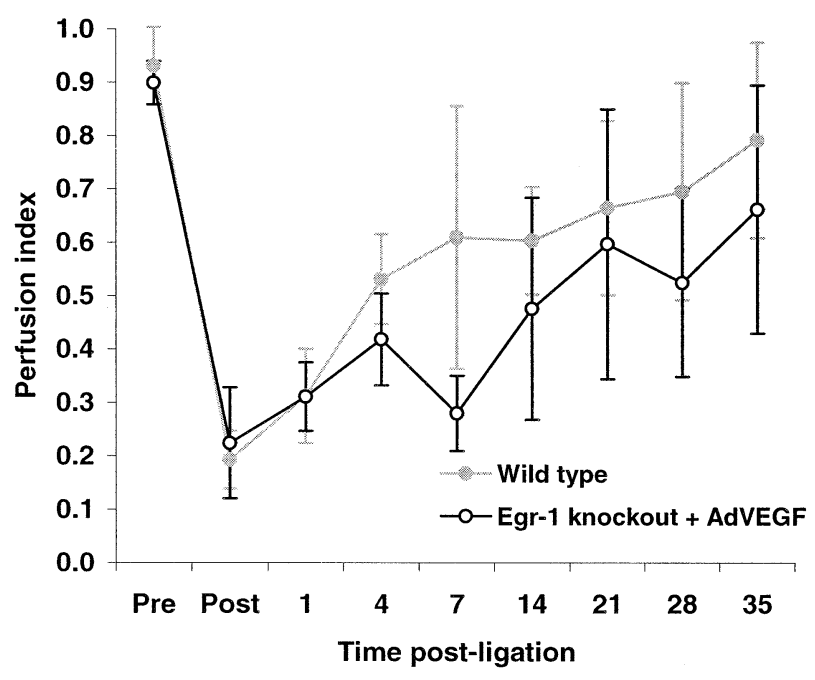

Figure 4. Distal hind limb perfusion after ipsilateral vascular excision in Egr1 knockout mice treated with AdVEGF. For comparison purposes, shaded curve shows pattern of recovery in wild-type mice, as shown in Figure 2.

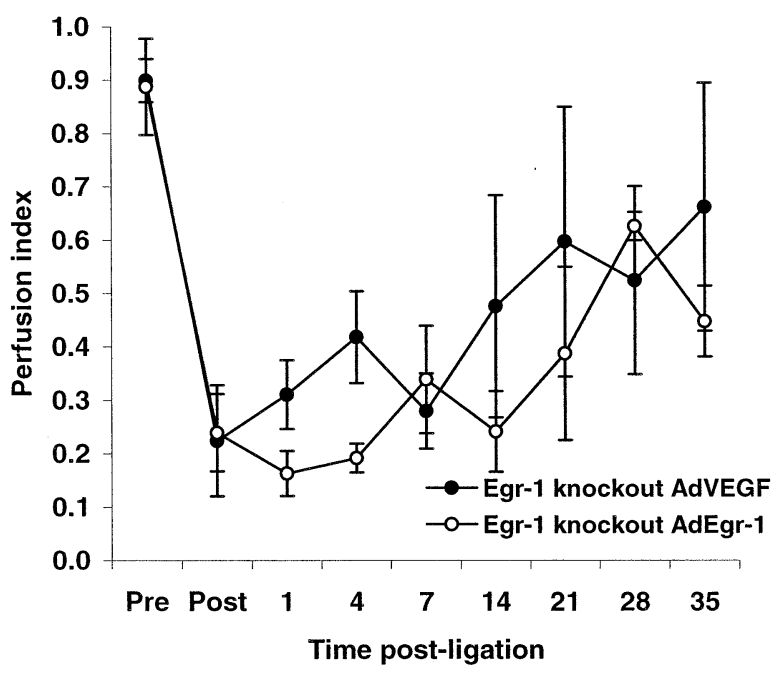

Figure 5. Distal hind limb perfusion after ipsilateral vascular excision in Egr1 knockout mice treated with AdEgr. For comparison purposes, filled circles show pattern of recovery in AdVEGFtreated knockouts, as shown in Figure 4. Difference in perfusion from AdVEGF-treated Egr1 knockout animals on postligation day 35 was not significant.

mechanisms creates powerful amplification loops that appear to be ideally configured for a critical neovascularization response to vascular occlusion.

Taken with the previous demonstration that shear stress can upregulate Egrl expression, ${ }^{18-20}$ and consistent with the observations that proximal tissues in the setting of vascular occlusion are not ischemic, ${ }^{9,10}$ the demonstration in the present study that Egrl expression is upregulated in presumably nonischemic vascular tissues upstream from a vascular ligation site supports our hypothesis that factors other than ischemia may play a role in reperfusion after vascular occlusion. Additional studies would, however, need to be performed to fully test this hypothesis, specifically including the demonstration of upregulation of EGR-1 protein, as opposed to messenger RNA expression, and the demonstration of upregulated Egrl expression in nonischemic cells in this model.

These studies also suggest that EGR-1 plays a critical role in the normal revascularization response to acute vascular occlusion that may take precedence over other, apparently nonredundant, signaling pathways implicated in the ischemia and revascularization response mechanisms, such as the hypoxia-inducible factor pathway. Previous evidence that EGR-1 can upregulate VEGF expression, for example, is consistent with this finding. ${ }^{16-20}$ Conversely, although a greater number of animals would need to be examined to resolve any potential differences between the therapeutic effects of VEGF relative to EGR-1, the limb salvage provided by VEGF in the current studies also reaffirms the ability of VEGF, and presumably other downstream growth factors, to induce physiologically meaningful vascularization, in this case, even in the absence of an intact Egrl pathway.

In light of evidence that EGR-1, like other transcription factors, can activate the expressions of a number of vascular development genes, it is possible that EGR-1 can induce vasculogenesis and collateral vessel formation to an extent that exceeds the angiogenesis generated by administration of single growth factors such as VEGF. Although these considerations are appealing conceptually, additional studies will need to be performed to confirm the role of EGR-1 in native arteriogenesis and to determine whether the use of EGR-1 and related factors might yield important new and more robust vasculogenic therapeutics than the use of single growth factors, such as VEGF, for the treatment of atherosclerosis and vascular occlusive disease.

\section{References}

1. Zhang QX, Magovern CJ, Mack CA, Budenbender KT, Ko W, Rosengart TK. Vascular endothelial growth factor is the major angiogenic factor in omentum: mechanism of the omentum-mediated angiogenesis. J Surg Res. 1997;67:147-54.

2. Brogi E, Wu T, Namiki A, Isner JM. Indirect angiogenic cytokines upregulate VEGF and bFGF gene expression in vascular smooth muscle cells, whereas hypoxia upregulates VEGF expression only. Circulation. 1994;90:649-652.

3. Li J, Brown LF, Hibberd MG, Grossman JD, Morgan JP, Simons M. VEGF, flk-1, and flt-1 expression in a rat myocardial infarction model of angiogenesis. Am J Physiol. 1996;270(5 Pt 2):H1803-11.

4. Waltenberger J, Mayr U, Pentz S, Hombach V. Functional upregulation of the vascular endothelial growth factor receptor KDR by hypoxia. Circulation. 1996;94:1647-54.

5. Longlan CJ. The collateral circulation of the limb. Ann R Coll Surg Engl. 1953;13:161-81. 
6. Pasyk S, Schaper W, Schaper J, Pasyk K, Miskiewicz G, Steinseifer B. DNA synthesis in coronary collaterals after coronary artery occlusion in conscious dog. Am J Physiol. 1982;11:H1031-7.

7. Freedman SB, Isner JM. Therapeutic angiogenesis for coronary artery disease. Ann Intern Med. 2002;136:54-71.

8. Simons M, Bonow RO, Chronos NA, Cohen DJ, Giordano FJ, Hammond $\mathrm{HK}$, et al. Clinical trials in coronary angiogenesis: issues, problems, consensus: an expert panel summary. Circulation. 2000; 102:E73-86.

9. Ito WD, Arras M, Scholz D, Winkler B, Htun P, Schaper W. Angiogenesis but not collateral growth is associated with ischemia after femoral artery occlusion. Am J Physiol. 1997;42(3 Pt 2):H1255-65.

10. Deindl E, Buschmann I, Hoefer IE, Podzuweit T, Boengler K, Vogel $\mathrm{S}$, et al. Role of ischemia and of hypoxia-inducible genes in arteriogenesis after femoral artery occlusion in the rabbit. Circ Res. 2001; 89:1-9.

11. Hershey JC, Baskin EP, Glass JD, Hartman HA, Gilberto DB, Rogers IT, et al. Revascularization in the rabbit hindlimb: dissociation between capillary sprouting and arteriogenesis. Cardiol Res. 2001;49: 618-25.

12. Heil M, Clauss M, Suzuki K, Buschmann IR, Willuweit A, Fischer S, et al. Vascular endothelial growth factor (VEGF) stimulates monocyte migration through endothelial monolayers via increased integrin expression. Eur J Cell Biol. 2000;79:850-7.

13. Ito WD, Arras M, Winkler B, Scholz D, Schaper J, Schaper W. Monocyte chemotactic protein-1 increases collateral and peripheral conductance after femoral artery occlusion. Circ Res. 1997;80:829-37.

14. Schaper W, Ito WD. Molecular mechanisms of coronary collateral vessel growth. Circ Res. 1996;79:911-9.

15. Carmeliet P. Mechanisms of angiogenesis and arteriogenesis. Nat Med.. 2000;6:389-95.

16. Yan SF, Fujita T, Lu J, Okada K, Shan Zou Y, Mackman N, et al. Egr-1, a master switch coordinating upregulation of divergent gene families underlying ischemic stress. Nat Med. 2000;6:1355-61.

17. Gashler A, Sukhatme VP. Early growth response protein (EGR-1): prototype of a zinc-finger family of transcription factors. Prog Nucleic Acid Res Mol Biol. 1995;50:191-224.

18. Khachigian LM, Collins T. Inducible expression of Egr-1-dependent genes: a paradigm of transcriptional activation in vascular endothelium. Circ Res. 1997;81:457-61.
19. Silverman ES, Collins T. Pathways of Egr-1 mediated gene transcription in vascular biology. Am J Pathol. 1999;154:665-70.

20. Braddock M, Schwachtgen JL, Houston P, et al. Fluid shear stress modulation of gene expression in endothelial cells. Am J Physiol. 1998;13:241-6.

21. Mechtcheriakova D, Schabbauer G, Lucerna M, Clauss M, De Martin $\mathrm{R}$, Binder BR, et al. Specificity, diversity, and convergence in VEGF and TNF-alpha signaling events leading to tissue factor up-regulation via EGR-1 in endothelial cells. FASEB J. 2001;15:230-42.

22. Lee SL, Sadovsky Y, Swirnoff AH, Polish JA, Goda P, Gavrilina G, et al. Luteinizing hormone deficiency and female infertility in mice lacking the transcription factor NGFI-A (Egr-1). Science. 1996;273: 1219-21.

23. Tourtellotte WG, Nagarajan R, Auyeung A, Mueller C, Milbrandt J. Infertility associated with incomplete spermatogenic arrest and oligozoospermia in Egr 4-deficient mice. Development. 1999;126:5061-71.

24. Hersh J, Crystal RG, Bewig BB. Modulation of gene expression after replication deficient recombinant adenovirus-mediated gene transfer by the product of a second adenovirus vector. Hum Gene Ther. 1995;2:124-31.

25. Rosenfeld MA, Yoshimura K, Trapnell BC, Yoneyama K, Rosenthal ER, Dalemans W, et al. In vivo transfer of the human cystic fibrosis transmembrane conductance regulator gene to the airway epithelium. Cell. 1992;68:143-55.

26. Magovern CJ, Mack CA, Zhang J, Rosengart TK, Isom OW, Crystal RG. Regional angiogenesis induced in nonischemic tissue by an adenoviral vector expressing vascular endothelial growth factor. Hum Gene Ther. 1997;8:215-27.

27. McCaffrey TA, Fu C, Du B, Eksinar S, Kent KC, Bush H, et al. High-level expression of Egr-1 and Egr-1-inducible genes in mouse and human atherosclerosis. J Clin Invest. 2000;105:653-62.

28. Hirasawa T, Ohara T, Makino S. Genetic typing of the mouse ob mutation by PCR and restriction enzyme analysis. Exp Anim. 1997; 46:75-8.

29. Couffinhal T, Silver M, Zheng LP, Kearney M, Witzenbichler B, Isner JM. Mouse model of angiogenesis. Am J Pathol. 1998;152:1667-79.

30. Landesberg LJ, Ramalingam R, Lee K, Rosengart TK, Crystal RG. Upregulation of transcription factors in lung in the early phase of postpneumonectomy lung growth. Am J Physiol Lung Cell Mol Physiol. 2001;281:L1138-49. 